SAE paper 2009-01-0579. Copyright @ 2009 SAE International. This paper is posted on this site with permission from SAE International, and is for viewing only. Further use or distribution of this paper is not permitted without permission from SAE" 


\title{
Experimental and Theoretical Investigation into the Dynamics of a Half-Car with an Interconnected Passive Suspension
}

\author{
Wade Smith and Nong Zhang \\ Mechatronics and Intelligent Systems, University of Technology, Sydney, Australia
}

Copyright $\odot 2008$ SAE International

\begin{abstract}
In this paper, a previously derived theoretical model of an integrated hydraulically interconnected suspension (HIS) half-car system is experimentally validated. The paper outlines the development of the HIS fluid system model and its integration into a four degree-of-freedom, roll-plane half-car system. An experimental approach to validate the model is outlined, and the resulting purposebuilt half-car test facility is described in detail. Experimental results from both free and forced vibration testing are presented and compared with model-based simulations. In general, very good agreement is observed. Limitations of the testing approach and reasons for any discrepancies are discussed. Finally, the broader implications of the obtained results in terms of practical HIS system design are considered.
\end{abstract}

\section{INTRODUCTION}

Vehicle suspension design usually involves a trade-off between handling stability and ride comfort. A relatively stiff suspension, in general, provides good handling stability but poor ride comfort, and vice versa. One approach to overcoming this compromise is through the use of hydraulic or mechanical interconnections between the individual wheel stations (spring-damper elements). An interconnected suspension system is one in which a displacement at one wheel station can produce forces at other wheel stations [1].

Interconnected suspensions, in theory, allow the designer to achieve greater control over the stiffness and damping of each suspension mode (i.e., bounce, roll, pitch and warp). The designer of a conventional non-interconnected suspension, however, remains reliant on single-wheel stiffness and damping to implicitly define modal characteristics. The degree to which individual modes are controlled depends on the exact method and arrangement of interconnection used.

In recent experimental studies, vehicles with hydraulically interconnected suspension (HIS) systems displayed significantly improved handling capability in comparison to their non-interconnected 'equivalents' $[2,3]$. Meanwhile a recent theoretical study concluded that, for a half-car model (with 'typical' passenger vehicle parameters) subjected to a stochastic road input, the added roll stiffness achieved with an HIS system resulted in better ride comfort and smaller tire normal force fluctuations than if the increased roll stiffness had been achieved with a stiffer conventional suspension [4]. The study, however, did not involve any experimental validation, and a question remains as to the veracity of its conclusions.

In this paper, an experimental validation of that modeling approach is presented. First, the model and basic equations are briefly reviewed. Next, the purpose-built test facility is described and the experimental results presented. These results are then compared with the theoretical predictions. Finally, the implications of the results are discussed and conclusions are given.

\section{MODELING}

SYSTEM DESCRIPTION - The system studied in this paper consists of two subsystems: one mechanical, one hydraulic, as outlined below.

Mechanical subsystem - The conventional quarter-car approach to ride modeling is inadequate for the study of interconnected suspensions. In order to retain simplicity whilst still accounting for fluid interconnections between wheel stations, a lumped-mass four-degree-of-freedom (4-DOF), roll-plane half-car model is used in this investigation. Numerical simulations of a similar full-car model show that the half-car simplification is capable of capturing the essential dynamics of the system [5]. The half-car (as shown in Figure 1) consists of linear tire damping and springing, linear conventional suspension springing, and a roll-plane HIS system. The considered degrees-of-freedom are the vertical displacements of the unsprung masses, the vertical displacement of the sprung mass and the roll displacement of the sprung mass. Although the focus of this paper is on a roll-plane half-car, there is nothing about the theory or test rig that would prevent them being applied to a pitch-plane model. The theory could also easily be applied to a fullcar model. 
Hydraulic subsystem - A typical HIS system consists of: double-acting cylinders, which replace conventional suspension shock absorbers (as shown); diaphragmtype accumulators, which provide an 'air-spring' effect; damper valves, which provide the desired damping in various modes; three-way pipe junctions; flexible hydraulic hoses; and thin-walled pipeline elements.

There are two basic types of two-wheel interconnection schemes: anti-oppositional arrangements, which stiffen out-of-phase motion of the connected wheel stations, relative to in-phase motion; and anti-synchronous arrangements, which do the opposite [6]. In the context of the HIS with double-acting cylinders shown in Figure 1 , an anti-oppositional arrangement would require hydraulic lines set out diagonally (connecting the top-left chamber with the bottom-right one, and the top-right with the bottom-left), while an anti-synchronous scheme would require parallel pipelines. Both arrangements are examined in this paper.

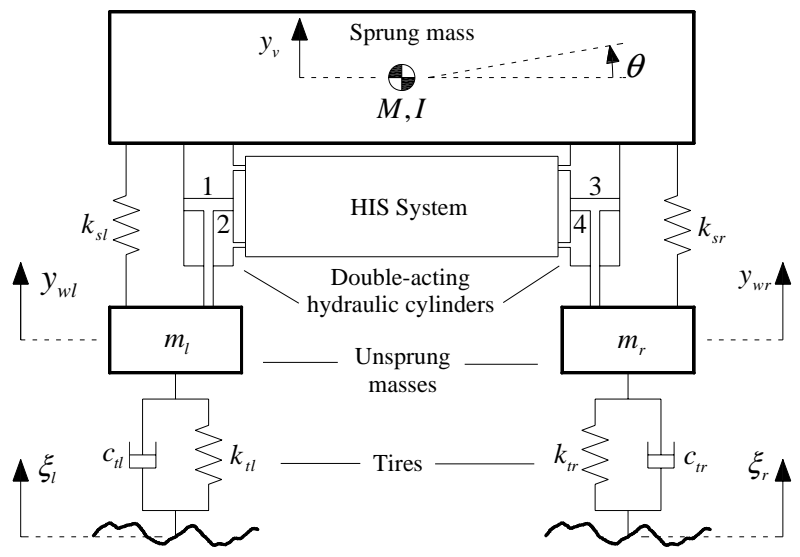

Figure 1: Schematic of a roll-plane half-car with an HIS

THEORETICAL APPROACH AND BASIC EQUATIONS - A derivation of the equations of motion of the integrated half-car and HIS system has been given elsewhere [7] and is not repeated in detail here; what follows is a brief outline.

Mechanical subsystem equations - Treating the pressure forces in the hydraulic cylinders as external loads acting on the vehicle, we obtain the equation of motion for the system:

$$
\mathbf{M y}+\mathbf{C} \dot{\mathbf{y}}+\mathbf{K y}=\mathbf{D}_{1} \mathbf{A p}(t)+\mathbf{f}_{\mathbf{G}}(t)
$$

where $\mathbf{M}, \mathbf{C}$ and $\mathbf{K}$ are the mass, damping and stiffness matrices, respectively; $\mathbf{y}=\left[y_{w l}, y_{w r}, y_{v}, \theta\right]^{T}$ is the displacement vector and $\mathbf{p}=\left[p_{1}, p_{2}, p_{3}, p_{4}\right]^{T}$ is the pressure vector (where the subscript numerals relate to the cylinder chambers numbered in Figure 1); $\mathbf{D}_{\mathbf{1}} \mathbf{A p}(t)$ and $\mathbf{f}_{\mathbf{G}}(t)$ represent, respectively, the pressure forces in the hydraulic cylinders and the forces due to ground excitation - other external forces are omitted.
As well as the pressure vector, the hydraulic cylinder force is comprised of the area matrix, $\mathbf{A}=\operatorname{diag}\left(A_{1}, A_{2}, A_{3}, A_{4}\right)$ - which represents the surface area of the piston in the corresponding chamber - and a linear transformation matrix, $\mathbf{D}_{\mathbf{1}}$.

Mechanical-fluid boundary equations - The mechanicalfluid system boundary conditions are treated as ideal, with all piston motion transferred into fluid flow. The boundary flow equation can thus be written:

$$
\mathbf{q}(t)=\mathbf{A D}_{2} \dot{\mathbf{y}}
$$

where the flow vector $\mathbf{q}=\left[q_{1}, q_{2}, q_{3}, q_{4}\right]^{T}$ and $\mathbf{D}_{2}$ is a linear transformation matrix.

Hydraulic subsystem equations - To solve Eqs. (1) and (2), a fluid system equation is needed which relates $\mathbf{p}$ and $\mathbf{q}$. This can be done using the linear hydraulic impedance method, which is computationally efficient and uses equations of the form $\mathbf{Q}(s)=\mathbf{Z}(s)^{-1} \mathbf{P}(s)$ [8]. $\mathbf{Z}$ is the system impedance matrix, which is derived using the transfer matrix method by multiplying the impedance characteristics of the individual fluid system elements, as detailed in [7].

Integrated system equations of motion - The fluid system impedance equation can be combined with the Laplace transform of Eqs. (1) and (2) to obtain the complete integrated system equation of motion:

$$
\left(s^{2} \mathbf{M}+s \overline{\mathbf{C}}(s)+\mathbf{K}\right) \mathbf{Y}(s)=\mathbf{F}_{\mathbf{G}}(s)
$$

in which $\overline{\mathbf{C}}(s)=\mathbf{C}+\mathbf{C}^{\prime}(s)$ is the complex frequency dependent system damping matrix, which includes both the mechanical system damping matrix $\mathbf{C}$, and $\mathbf{C}^{\prime}(s)=-\mathbf{D}_{1} \mathbf{A Z}(s) \mathbf{A} \mathbf{D}_{2}$, the damping contribution from the hydraulic subsystem.

Integrated system frequency response functions - The system's frequency response functions (FRFs) can be found by expressing the road force vector as $\mathbf{F}_{\mathbf{G}}(s)=\overline{\mathbf{F}}(s) \bar{\xi}(s) . \quad \bar{\xi}=\left[\xi_{l}, \xi_{r}, 0,0\right]^{T}$ is a vector of the road displacement from the equilibrium position, and $\overline{\mathbf{F}}$ is a $4 \times 4$ matrix comprising all zero elements except the upper two diagonal terms, $\bar{F}_{11}(s)=s c_{t l}+k_{t l}$ and $\bar{F}_{22}(s)=s c_{t r}+k_{t r}$. Eq. (3) can thus be written in the form:

$$
\mathbf{B}(s) \mathbf{Y}(s)=\overline{\mathbf{F}}(s) \bar{\xi}(s)
$$

We may now define the FRFs matrix for the half-car:

$$
\mathbf{H}(s)=\mathbf{Y}(s) / \bar{\xi}(s)=\mathbf{B}^{-1}(s) \overline{\mathbf{F}}(s)
$$


Upon setting $s=j \omega$, the FRFs matrix describes the system displacement response to any harmonic road excitation. The FRFs for this system have been published elsewhere and are not repeated here [4].

HYDRAULIC SYSTEM AND COMPONENT MODELS The hydraulic system is modeled using the impedance method, which is most often applied in the frequency domain and requires linearisation of each component. The technique accounts for fluid resistance (pressure loss), inductance (fluid inertia) and capacitance (fluid compressibility). The method makes use of the onedimensional, two-port two-node) hydraulic component representation [9], in which the pressure and flow at adjacent nodes are related by a transmission matrix, $\mathbf{T}$ :

$\left[\begin{array}{l}P(s) \\ Q(s)\end{array}\right]_{D}=\left[\begin{array}{ll}T_{11}(s) & T_{12}(s) \\ T_{21}(s) & T_{22}(s)\end{array}\right] \cdot\left[\begin{array}{l}P(s) \\ Q(s)\end{array}\right]_{U}$

where the subscripts ' $D$ ' and ' $U$ ' mean 'downstream' and 'upstream', respectively.

Once a transmission matrix for each component is determined, the transfer matrix method [10] can be applied to connect all the nodal states within the circuits. The accuracy of this approach depends on the capacity to precisely model the impedance characteristics of each fluid element. The assumption that such a capacity exists underpins the proposed modeling procedure.

Present space limitations preclude a thorough explanation of the component models used in the simulations - further information can be found in [7]. It should be noted, however, that the damper valves which provide the desired level of damping in a given suspension mode - are modeled here as purely resistive elements, with a linear loss coefficient, $k_{v}$ :

$$
k_{v}=\Delta p / q
$$

where $\Delta p$ is the pressure drop across the valve and $q$ is the volumetric flow rate of the fluid through the valve.

\section{EXPERIMENTATION}

INTRODUCTION AND RATIONALE - An attempt is made here to experimentally validate the modeling approach outlined above. This is done with a purposebuilt, 4-DOF, half-car test rig, specially designed at the University of Technology, Sydney (UTS). The test program consists of both free and forced vibration testing. The free vibration testing is used to determine the stiffness and damping of the bounce and roll modes, from which the value of $k_{v}$ is estimated. This value is used in simulations to compare the experimental forced vibration data with the theoretical predictions.

DESCRIPTION OF TEST RIG - The free and forced vibration experiments were performed on the half-car test rig shown in Figures 2, 3 and 4. The rig was designed, manufactured and operated at UTS.

General layout - The apparatus was designed specifically to operate like the half-car model introduced earlier. The test set-up consists of: two rigid unsprung masses, each constrained with low friction roller bearings to only one vertical degree of freedom; and the rigid sprung mass, with two degrees of freedom: bounce and roll. One double-acting hydraulic cylinder is placed at each wheel station, so the rig can accommodate any two-wheel HIS arrangement (anti-oppositional or antisynchronous). The sprung mass and roll inertia can easily be varied, and the rig can accommodate rigid or conventional rubber top mounts. External force application, when required, is provided via an external servovalve hydraulic system and an actuator attached rigidly to the underside of one of the unsprung masses.

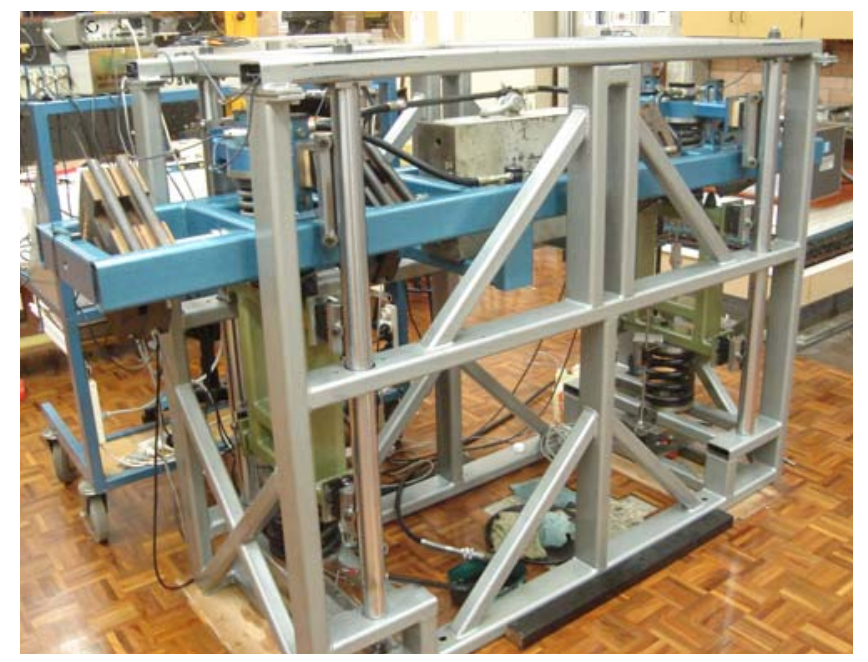

Figure 2: Half-car test rig: main view

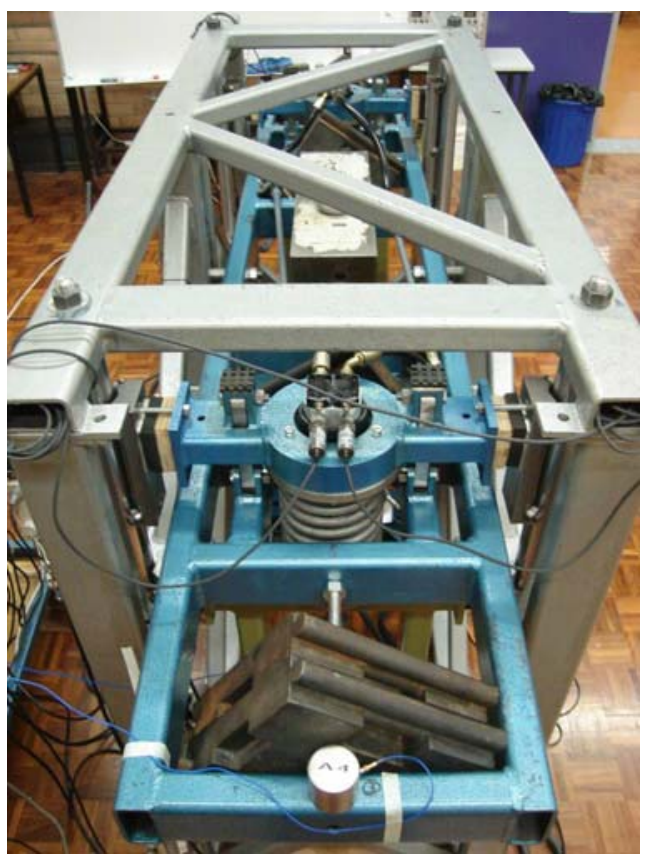

Figure 3: Half-car test-rig: top view 
All the results presented in this paper relate to testing with rubber top mounts and with four sprung mass/roll inertia combinations. The HIS mean system pressure and pipeline arrangement were also varied throughout the testing.

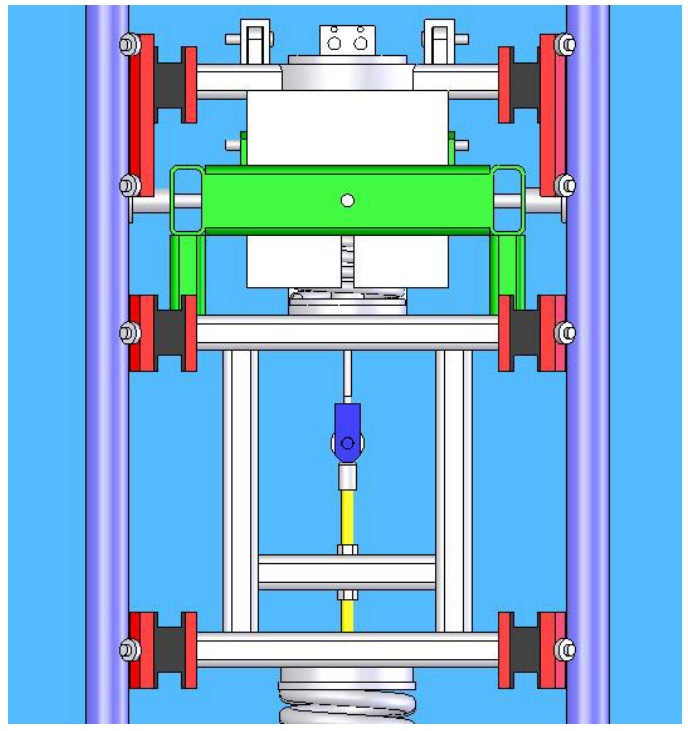

Figure 4: Half-car test-rig: side view, showing guide rails and roller bearings

Hydraulic system - Two hydraulic system arrangements were tested: anti-oppositional (free and forced vibration) and anti-synchronous (forced vibration only), shown in Figures 5 and 6, respectively. Experiments with the antioppositional set-up were performed both with (free and forced vibration) and without (free vibration only) damper valves. The anti-synchronous tests were all performed with the damper valves installed. A steel pipeline of 13.3 $\mathrm{mm}$ diameter and $500 \mathrm{~mm}$ length was used, and two $12.7 \mathrm{~mm}$ diameter flexible hoses - of $300 \mathrm{~mm}$ (Hose 1) and $500 \mathrm{~mm}$ (Hose 2) length - were used concurrently.

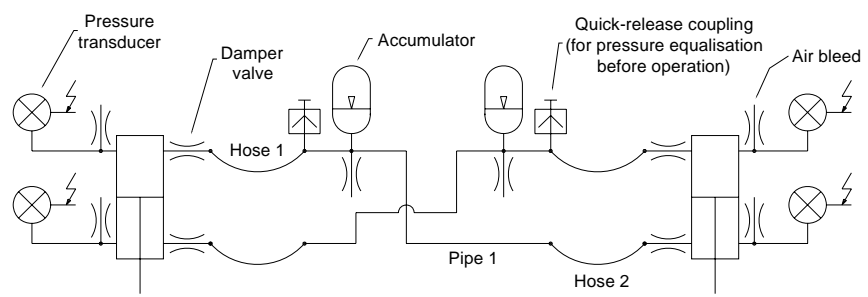

Figure 5: Hydraulic layout for anti-oppositional half-car testing

The mean system pressure, $\bar{p}$, for the free vibration testing was 10 bar; pressures of 15, 20 and 25 bar were used for each set of forced vibration tests. The accumulators are $320 \mathrm{cc}$, and were pre-charged to 2 bar gauge pressure. The four one-way 'cylinder' damper valves - positioned on each cylinder port - consist of a shim-stack-and-spring arrangement, chosen during the free vibration testing to achieve a bounce damping ratio of approximately 40\%. Additional (mode-dependent) damping can be achieved by adding 'accumulator' damper valves, but these were not used in any of the tests. Each hydraulic line includes a quick release coupling to allow simultaneous pressure charging of both circuits, thus ensuring pressure equalization throughout the system.

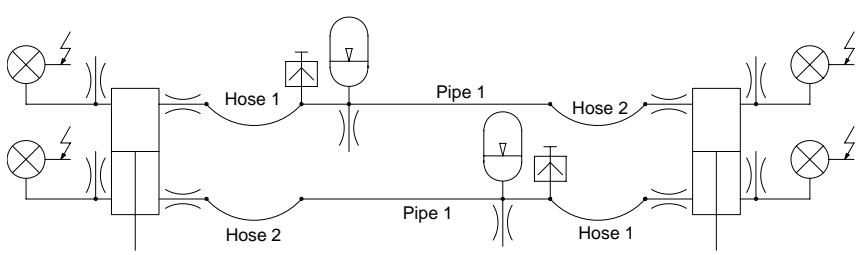

Figure 6: Hydraulic layout for anti-synchronous half-car testing

Mechanical system - The mechanical subsystem is described by the properties shown in Tables 1 and 2 . For the free vibration testing, the sprung mass and roll inertia were varied between mass configurations 1, 2 and 3 . In the forced vibration tests, only configuration 4 was used.

Table 1: Constant parameters of the half-car experimental rig mechanical subsystem

\begin{tabular}{|c|c|c|c|}
\hline Symbol & Value & Units & Description \\
\hline$b_{j}$ & 0.75 & $\mathrm{~m}$ & $\begin{array}{l}\text { Distance from c.g. to suspension strut } \\
\text { (subscript } j=r, l \text { ) }\end{array}$ \\
\hline$m_{j}$ & $51.1 / 49.4$ & $\mathrm{~kg}$ & $\begin{array}{l}\text { Unsprung mass with/without hydraulic } \\
\text { system installed }\end{array}$ \\
\hline$k_{s l}, k_{s r}$ & $20.6,20.4$ & $\mathrm{kN} \mathrm{m}^{-1}$ & $\begin{array}{l}\text { Mechanical suspension spring stiffness } \\
\text { (left, right) }\end{array}$ \\
\hline$k_{t l}, k_{t r}$ & $182.8,185.6$ & $\mathrm{kN} \mathrm{m}^{-1}$ & Tire spring stiffness (left, right) \\
\hline$C_{t j}$ & 0 & $\mathrm{~N} \mathrm{~s} \mathrm{~m}^{-1}$ & $\begin{array}{l}\text { Tire damping (i.e., only a spring is } \\
\text { used) }\end{array}$ \\
\hline
\end{tabular}

Table 2: Variable mass properties of the half-car experimental rig

\begin{tabular}{|c|c|c|c|}
\hline Symbol & Value & Units & Description \\
\hline \multicolumn{4}{|c|}{ Mass configuration 1} \\
\hline$M$ & $648.8 / 645.7$ & $\mathrm{~kg}$ & $\begin{array}{l}\text { Sprung mass with/without hydraulic } \\
\text { system installed }\end{array}$ \\
\hline$I$ & $347.4 / 345.6$ & $\mathrm{~kg} \mathrm{~m}^{2}$ & $\begin{array}{l}\text { Sprung mass roll inertia with/without } \\
\text { hydraulic system installed }\end{array}$ \\
\hline \multicolumn{4}{|c|}{ Mass configuration 2} \\
\hline$M$ & $648.8 / 645.7$ & $\mathrm{~kg}$ & $\begin{array}{l}\text { Sprung mass with/without hydraulic } \\
\text { system installed }\end{array}$ \\
\hline$I$ & $271.7 / 269.9$ & $\mathrm{~kg} \mathrm{~m}^{2}$ & $\begin{array}{l}\text { Sprung mass roll inertia with/without } \\
\text { hydraulic system installed }\end{array}$ \\
\hline \multicolumn{4}{|c|}{ Mass configuration 3} \\
\hline$M$ & $648.8 / 645.7$ & $\mathrm{~kg}$ & $\begin{array}{l}\text { Sprung mass with/without hydraulic } \\
\text { system installed }\end{array}$ \\
\hline$I$ & $159.3 / 157.6$ & $\mathrm{~kg} \mathrm{~m}^{2}$ & $\begin{array}{l}\text { Sprung mass roll inertia with/without } \\
\text { hydraulic system installed }\end{array}$ \\
\hline \multicolumn{4}{|c|}{ Mass configuration 4} \\
\hline$M$ & 599.6 & $\mathrm{~kg}$ & $\begin{array}{l}\text { Sprung mass with hydraulic system } \\
\text { installed }\end{array}$ \\
\hline$I$ & 261.3 & $\mathrm{~kg} \mathrm{~m}^{2}$ & $\begin{array}{l}\text { Sprung mass roll inertia with hydraulic } \\
\text { system installed }\end{array}$ \\
\hline
\end{tabular}


External force application - The forced vibration testing was performed with a single harmonic input applied directly to the left unsprung mass with a double-acting hydraulic cylinder. This, in effect, reduced the mechanical half-car system to one determined and three undetermined degrees-of-freedom. The actuator was driven by an external electrohydraulic servovalve system. The input force was governed by a constant amplitude, harmonic displacement control signal from a custom Moog Hydraulic Servo Controller and a Wavetek 75 Arbitrary Waveform Generator.

TEST METHODOLOGY - Prior to undertaking each test, whether free or forced vibration, a standard procedure was followed to ensure that the rig was set-up correctly. This included: checking that the circular guide rails were all purely vertical; checking that there was (roughly) uniform contact between all the roller bearings and guide rails; ensuring that the static pressure was equal in both lines (easily achieved by charging the system through the removable pressure equalizing line); minimizing the amount of entrained air in the oil (by careful bleeding after each hydraulic component change); and setting the pistons to be positioned at the midpoint of the stroke.

Free vibration - The free vibration tests involved a series of single, human-applied, short duration impulses exerted on the sprung mass. First, four such impulses were applied to the left side of the sprung mass, then four to the right side. The magnitudes of all eight impulses were approximately equal, yet because the force was human-applied, variations inevitably occurred. After each impulse, the system was left to return to its equilibrium state before another impulse was applied. Each of the eight free decay responses was recorded and analyzed, as outlined in [11]. The main objective of the testing was to determine the (approximate) bounce and roll natural frequencies and damping ratios. This was done by averaging the eight responses and by assuming that the duration of the applied force was infinitesimal. These damping ratios were then used to calculate the approximate damper valve loss coefficients for use in the forced vibration response predictions.

A secondary objective was to establish the level of (undesired) damping produced by friction in the guide bearings and the structural damping in the suspension and tire springs. This was determined by conducting free vibration tests without the hydraulic system installed. Aside from these tests, experiments were also performed with the anti-oppositional hydraulic set-up, both with and without damper valves installed. In both cases, the mean system pressure was set to 10 bar.

Forced vibration - The forced vibration tests were performed by applying a harmonic input to the left unsprung mass. The frequency of the input, of constant $\pm 2.6 \mathrm{~mm}$ nominal amplitude, was varied in small increments $(\leq 0.25 \mathrm{~Hz})$ and data (the acceleration of the sprung and unsprung masses) were recorded at each frequency step.
Due to the high transmissibilities involved, forced vibration tests were not carried out on the undamped half-car set-up; testing was only performed with the dampers installed. The hydraulic arrangement, however, was switched between anti-oppositional and antisynchronous, and testing was performed at 15, 20 and 25 bar with both arrangements. As most of the vehicle weight was borne by the suspension springs, a change in mean system pressure did not change the ride height significantly. For example, a change in mean pressure of 10 bar altered the ride height by about $4.6 \mathrm{~mm}$. During all tests, the temperature of the servovalve was monitored to ensure that it did not exceed $90^{\circ} \mathrm{C}$.

The main objective of the forced vibration testing was to determine, relative to the left unsprung mass, the transmissibilities for the bounce, roll and right unsprung mass motion variables. This allows a direct comparison with the theoretical frequency response functions previously described.

APPLICATION OF MATHEMATICAL MODEL - The general approach used to model the test rig was introduced under 'Modeling'. As the damper valves are not modeled parametrically, an approach for deciding on the value of the loss coefficient ( $k_{v}$ from Eq. (7)) must be developed. In this paper, two such approaches were taken.

Theory 1 - First, an iterative approach was used to determine $k_{v}$ by matching the damping ratios obtained in the free vibration testing. These loss coefficients were then used in the initial simulations - hereafter denoted 'Theory 1' - for comparison with the forced vibration test results.

Theory 2 - The second approach for determining $k_{v}$ was based on the forced vibration testing. The new value for the coefficient was calculated by minimizing the sum-ofsquares error, $\mathcal{E}$, between the theoretical and experimental transmissibilities over the $n$ data points in the frequency range, $f_{i}$, from 0 to $20 \mathrm{~Hz}$ :

$\varepsilon=\frac{1}{n} \sum_{i=1}^{n}\left\{\left[\Delta \bar{y}_{w r}\left(f_{i}\right)\right]^{2}+\left[\Delta \bar{y}_{v}\left(f_{i}\right)\right]^{2}+\left[\Delta \bar{\theta}\left(f_{i}\right)\right]^{2}\right\}$

where, for a given variable $y$ :

$$
\Delta \bar{y}\left(f_{i}\right)=\frac{\left|y^{t}\left(f_{i}\right)\right|}{\left|y_{w l}^{t}\left(f_{i}\right)\right|}-\frac{\left|y^{e}\left(f_{i}\right)\right|}{\left|y_{w l}^{e}\left(f_{i}\right)\right|}
$$

where the superscripts ' $\mathrm{t}$ ' and ' $\mathrm{e}$ ' denote 'theory' and 'experiment', respectively. Thus, for each test set-up, one 'best-fit' loss coefficient is determined based on all three transmissibilities. This approach is referred to as 'Theory 2' in the following sections. It should be noted, however, that the underlying theory behind 'Theory 1' and 'Theory 2' is identical; the labels are simply used to 
indicate the way in which the $k_{v}$ value has been determined.

\section{RESULTS}

FREE VIBRATION - The results from testing without the hydraulic system installed indicated that the unintentional damping in the system (e.g. guide bearing friction, structural damping in the springs, etc.) was very low ( $\zeta<1 \%$ for the bounce and roll modes in all tests). This suggests that the obtained results are unlikely to be significantly corrupted by external effects.

Table 3 shows the free vibration results - that is, the natural frequencies and damping ratios for the bounce and roll modes - for testing with the hydraulic system and damper valves installed. It was found that, in comparison to the system without hydraulics, the bounce mode was softened slightly by the hydraulic system - a finding consistent with simulations - and the roll mode, as expected, was significantly stiffened by it. The table also shows the approximate valve loss coefficients required, in simulations, to deliver the experimentally obtained bounce and roll damping ratios. It can be seen that in each case these values are identical $2.665 \times 10^{9} \mathrm{~kg} \mathrm{~s}^{-1} \mathrm{~m}^{-4}$ for the cylinder dampers; 0 , as expected, for the (uninstalled) accumulator dampers suggesting that the testing methodology was sufficiently robust to deliver repeatable results.

Table 3: Bounce and roll natural frequencies, damping ratios and approximate valve loss coefficients from free vibration testing: hydraulic system installed with damper valves; $\bar{p}=10$ bar

\begin{tabular}{|ccccccc|}
\hline & \multicolumn{2}{c}{ Bounce mode } & Roll mode & \multicolumn{2}{c|}{$\begin{array}{c}\text { Approx. } \boldsymbol{k}_{v} \times \mathbf{1 0}^{-9} \\
\left(\mathbf{k g ~ s}^{-1} \mathbf{m}^{-4}\right)\end{array}$} \\
\cline { 2 - 7 } Mass & $\omega_{n}$ & $\zeta(\%)$ & $\begin{array}{c}\omega_{n} \\
(\mathrm{rad} / \mathrm{s})\end{array}$ & $\zeta(\%)$ & $k_{v(c y l)}$ & $k_{v(a c c)}$ \\
\hline 1 & 7.85 & 40.9 & 12.45 & 17.5 & 2.665 & 0 \\
2 & 7.85 & 40.9 & 14.16 & 19.7 & 2.665 & 0 \\
3 & 7.85 & 40.9 & 18.94 & 25.2 & 2.665 & 0 \\
\hline
\end{tabular}

FORCED VIBRATION - The forced vibration results that is, the obtained transmissibilities, relative to the input at the left unsprung mass, of the right unsprung mass and the sprung mass bounce and roll modes - are shown in Figures 7 and 8 . Each of the plots shows the frequency responses for testing at mean pressures of 15,20 and 25 bar.

The differences between the anti-oppositional and antisynchronous arrangements can clearly be seen. The former (Figure 7) stiffens the roll mode significantly (giving a natural frequency in that mode of $3-4 \mathrm{~Hz}$, depending on system pressure) but leaves the bounce mode relatively soft. The latter (Figure 8), on the other hand, stiffens the bounce mode but not the roll mode. This is consistent with expectations, due to the nominal fluid flow paths in each mode. In the anti-oppositional arrangement, roll motion causes a large amount of fluid to flow into/out of the accumulators, which offer a resistance due to gas compressibility (often called the 'air spring' effect), giving added stiffness to the roll mode. While in the bounce mode, only a very small amount of fluid flows into the accumulators, so very little stiffness is added to that mode. In the anti-synchronous arrangement, the reverse is true. It is for this reason that interconnected suspensions are sometimes said to 'break the compromise' between ride and handling, as desirable levels of stiffness and damping for each mode can be achieved, at least in principle.

It is immediately apparent from the graphs that the mean system pressure has a significant effect on the transmissibility of the right wheel. In the anti-oppositional case, the roll mode is also significantly affected around its single peak, as is the bounce mode in the antisynchronous arrangement. As expected, at higher mean pressure, the accumulator 'air spring' is stiffer, thus generally leading to higher transmissibilities over most of the frequency range, as well as reduced damping.
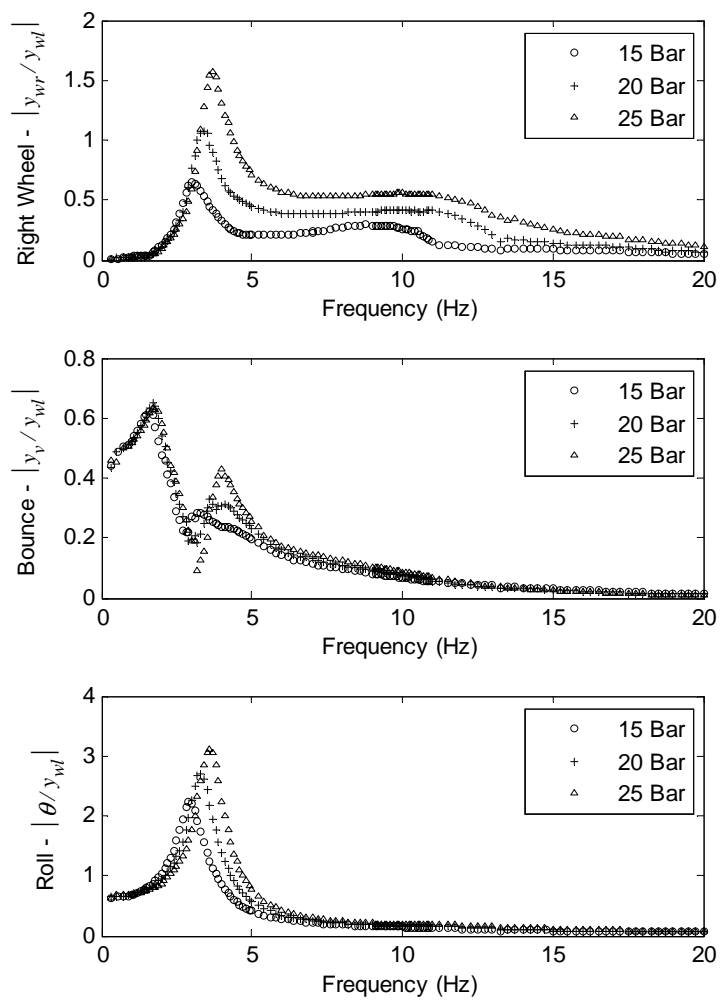

Figure 7: Transmissibilities from forced vibration testing: anti-oppositional arrangement; $\bar{p}=15,20,25$ bar

COMPARISON WITH THEORY - In this section, the experimental data for $\bar{p}=20 \mathrm{bar}$, presented in Figures 7 and 8 , are compared with the theoretical predictions 'Theory 1' and 'Theory 2'. The valve loss coefficients and corresponding sum-of-squares error terms for each experiment and modeling approach are shown in Table 4. And in Figures 9 and 10, the theoretical 
transmissibilities obtained with Theory 1 and Theory 2 are plotted with the experimental data.

From Table 4 it can be seen that, compared with Theory 1 , Theory 2 achieves only a slightly better fit with the experimental data in the anti-synchronous test. In the anti-oppositional test, however, the best-fit valve loss coefficient is $10 \%$ higher than that obtained in the free vibration testing, and the resulting error term is $20 \%$ lower.
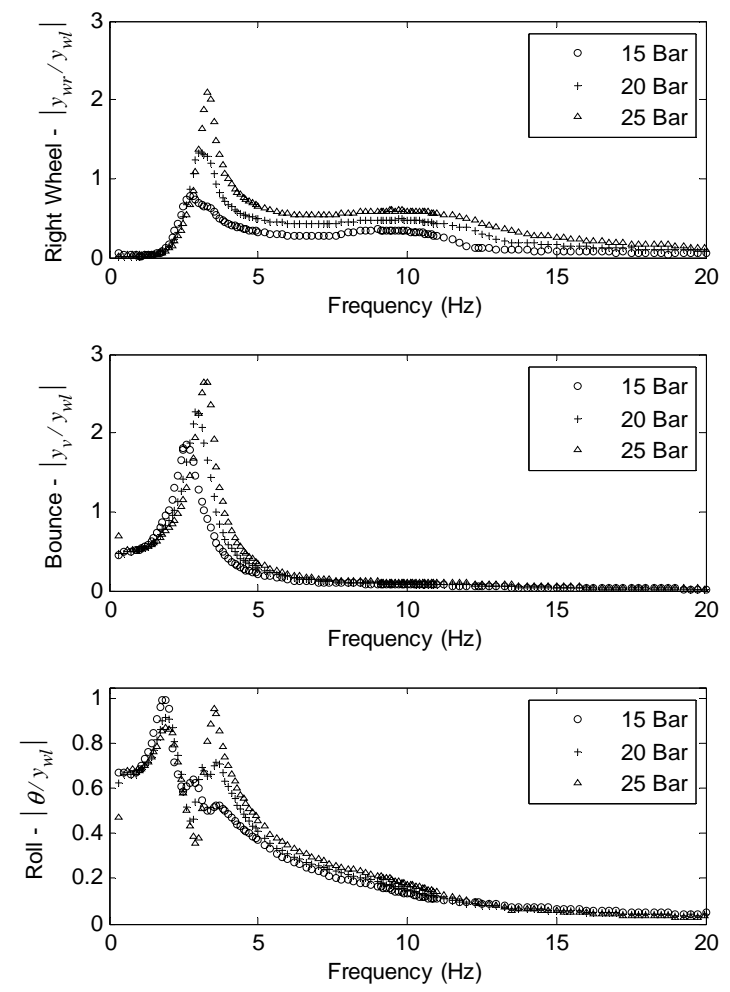

Figure 8: Transmissibilities from forced vibration testing: anti-synchronous arrangement; $\bar{p}=15,20,25$ bar

Table 4: Valve loss coefficients and sum-of-squares error from forced vibration testing: $\bar{p}=20$ bar

\begin{tabular}{|c|c|c|c|c|}
\hline \multirow{3}{*}{\begin{tabular}{|l} 
Arrangement \\
Anti-oppositional
\end{tabular}} & \multicolumn{2}{|c|}{ Theory 1} & \multicolumn{2}{|c|}{ Theory 2} \\
\hline & $\begin{array}{c}k_{v} \times 1 \\
\left(\mathrm{~kg} \mathrm{~s}^{-1}\right.\end{array}$ & $\mathcal{E} \times 10^{2}$ & $\begin{array}{l}k_{v} \times 1 \\
\left(\mathrm{~kg} \mathrm{~s}^{-}\right.\end{array}$ & $\mathcal{E} \times 10^{2}$ \\
\hline & 2.665 & 1.622 & 2.932 & 1.290 \\
\hline Anti-synchronous & 2.665 & 1.682 & 2.735 & 1.665 \\
\hline
\end{tabular}

The agreement between the modeling and the experimental data shown in Figures 9 and 10 is, in general, quite good. One point of note is that, with both arrangements, the right wheel damping around the wheel hop frequency $(\sim 10 \mathrm{~Hz})$ is slightly lower than predicted. This is most likely due to the nonlinearity in the damper valves; they may have been operating near the end of the 'transition region' [12], with the high wheel velocities associated with that mode fully opening the valves briefly.

The predicted roll response in the anti-oppositional arrangement and the bounce response in the antisynchronous case agree very well with the obtained data. One reason for this could be the higher transmissibilities involved rendering some of the unmodeled nonlinearities (e.g., friction in the guide bearings and the piston rod seals) less significant than in the other responses. Although a larger response amplitude is also likely to introduce other nonlinear effects (e.g., damper valve pressure losses, nonlinear 'air spring' effect, etc.), these have not caused discrepancies of any note between the two sets of data.

The least accurate predictions are of the antioppositional bounce response and the anti-synchronous roll response. In each of these plots, the trend of the curve matches the data points reasonably well, but the predicted response is shifted down the frequency range slightly. This is a potential topic for further investigation.
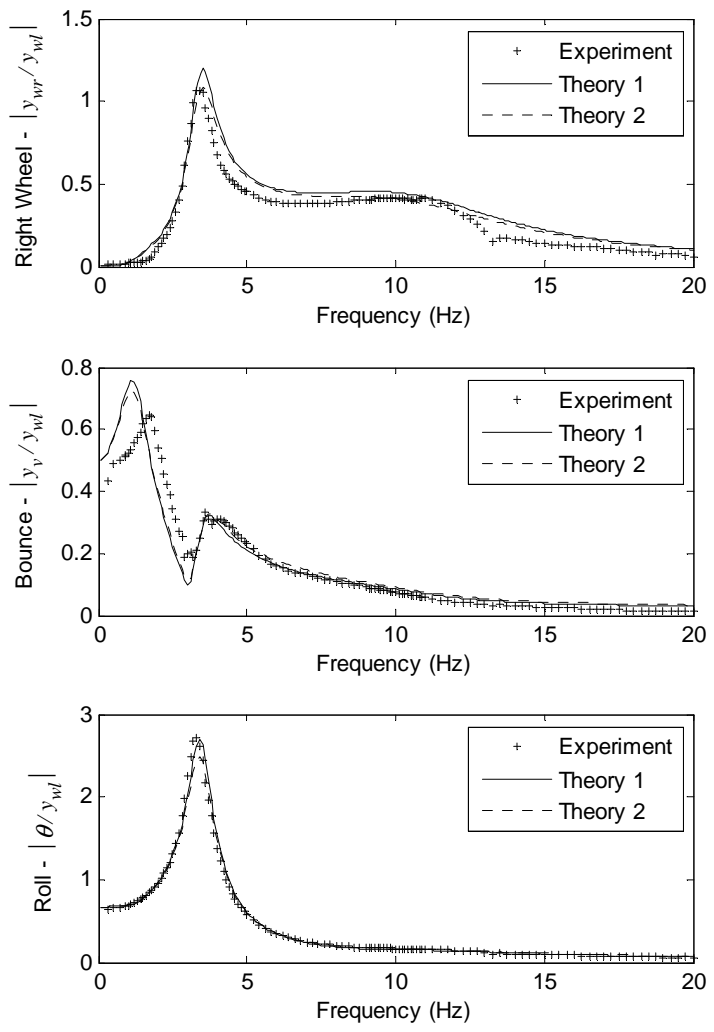

Figure 9: Comparison between experimental and theoretical frequency responses: anti-oppositional arrangement; $\bar{p}=20$ bar 

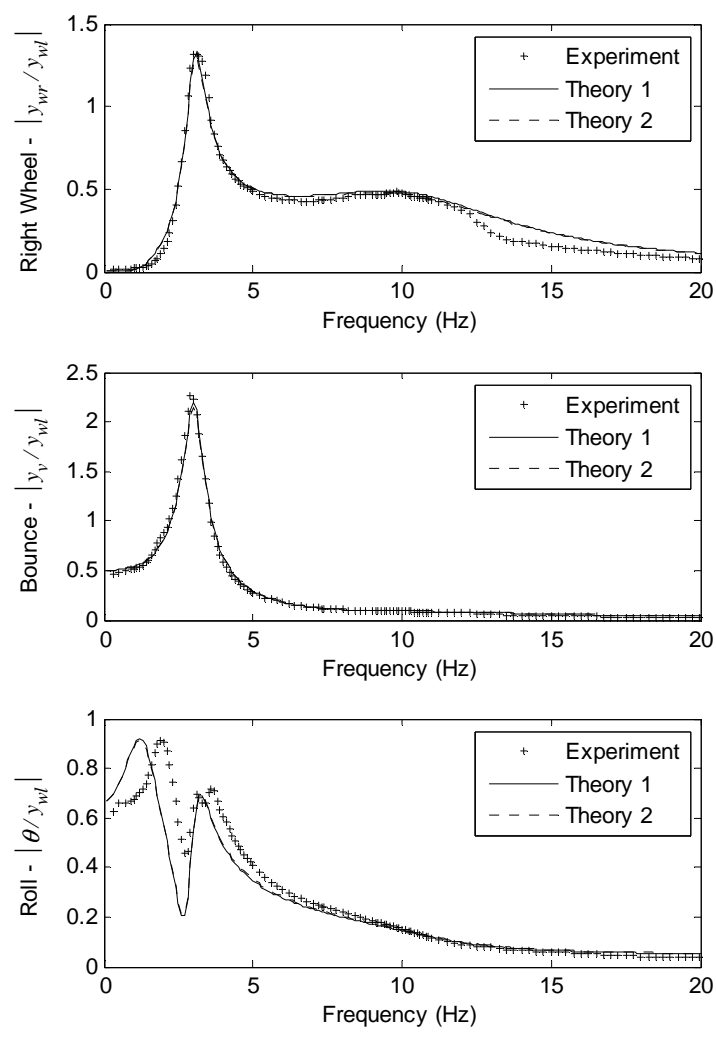

Figure 10: Comparison between experimental and theoretical frequency responses: anti-synchronous arrangement; $\bar{p}=20$ bar

\section{DISCUSSION}

UNMODELLED EFFECTS - The modeling used in the preceding section overlooked a number of factors that may have reduced the accuracy of the results. The most significant of these is almost certainly the damper valves. Due to the large number of components in the valve assembly (shims, valve body, pre-loaded spring, etc.), developing an accurate, parametric model of the dampers' pressure-flow properties presents a challenging undertaking.

Figure 11 shows these properties for a typical shock absorber damper valve [12]. A cutaway view of the valve itself is shown in Figure 12 [13]. The area of the graph referred to as 'Stage 1' corresponds to operation with the valve completely closed, the only flow passing through the slotted bleed shims. In 'Stage 2', the transition region, the valve gradually opens through the compression of the spring, until, in 'Stage 3', it reaches its fully open state. Thus stages 1 and 3 are governed essentially by constant-area flow dynamics, with a complex transition region linking the two. Accurately modeling this phenomenon would probably require the use of sophisticated CFD software [13], though the plots in the preceding section suggest that that level of detail may not be necessary for some purposes. A rough calculation of the loss coefficient - based only on the flow area in the bleed shims used on the test rig - gives a value of about $k_{v} \square 1.5 \times 10^{11} \mathrm{~kg} \mathrm{~s}^{-1} \mathrm{~m}^{-4}$, much larger than the results in Table 4 . It is clear, then, that the valves were opening during the tests, and that any parametric model for use in such circumstances must account for the transition region.

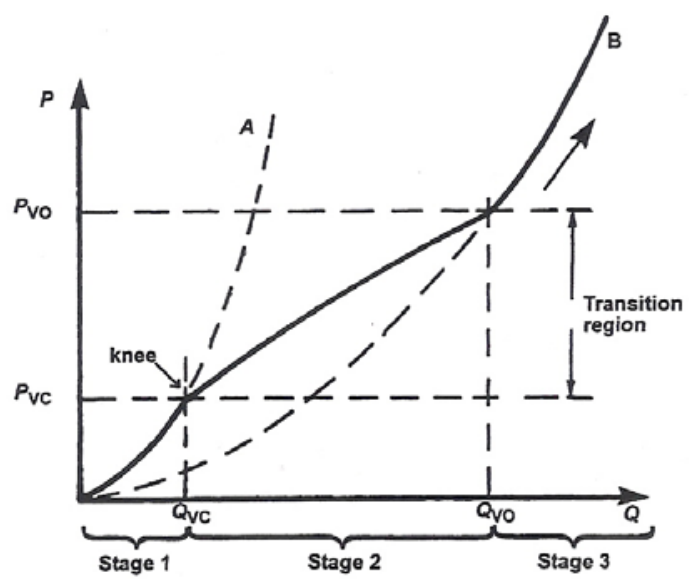

Figure 11: Pressure loss versus flow rate for a typical shock absorber damper valve [12]

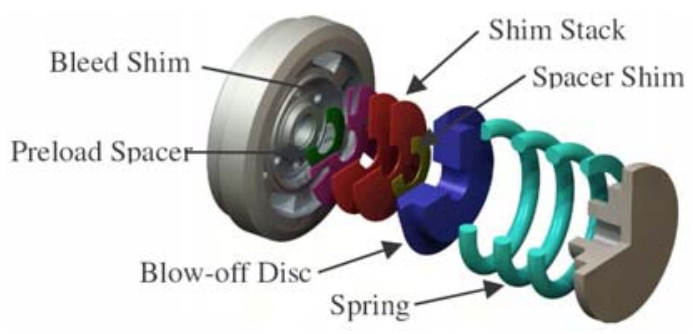

Figure 12: Cutaway view of damper valve [13]

Some simulations were performed incorporating the hydraulic cylinder's rubber top mounts into the model. They were treated as constant-stiffness spring elements, with a stiffness value supplied by the manufacturer. This, however, reduced the accuracy of the simulations, compared with both the 'Theory 1' and 'Theory 2' results. This may be because the mounts' stiffness is both frequency-dependent and nonlinear, neither of which is accounted for in the manufacturer's staticallyderived stiffness coefficient. Dynamic testing of the top mounts, to ascertain their stiffness and damping properties as a function of amplitude and frequency, would be a potential step in any subsequent investigation.

SUGGESTIONS FOR FURTHER TESTING - If the methodology proposed here is to be used in practice, there is a clear need to obtain accurate empirical hydraulic component models. No such testing has been undertaken in this investigation, but much work has previously been done by others in the field. In particular, researchers at the University of Bath have devised a robust experimental technique for determining the impedance characteristics of individual hydraulic 
components over a wide frequency range. It may even be possible to establish amplitude-dependent characteristics - in the form of, say, a frequencyamplitude map - in the more nonlinear components (e.g., valves), though incorporating that information into a practical vehicle model may be difficult. The interested reader is referred to the appropriate references for further information on experimental impedance determination $[9,14]$.

PRACTICAL DESIGN IMPLICATIONS - The experimental results clearly illustrate the significant effect that the mean system pressure and damper valve properties have on the frequency response of HISequipped vehicles. The bounce and roll responses, in particular, are of critical importance as they are directly related to the discomfort experienced by the vehicle occupants [15]. It is noted that in the forced vibration tests, the broad trends in the frequency responses were well predicted by the theory, suggesting a suitability for the model, as it stands, in the early stages of the vehicle design process, when quickly establishing general trends is of principle importance.

The most challenging aspect to extending the generality of the model lies, almost certainly, with the damper valves. In hydraulic impedance terms, these may exhibit capacitive or inductive characteristics at very high frequencies [16,17], but a purely resistive model is probably adequate for any vehicle ride study. This resistance, however, is not a constant function of either amplitude or frequency, and further investigation is required to establish the conditions under which such an assumption is valid. Even so, it was found that using the free vibration tests to determine the valve loss coefficient produced a value that returned reasonably accurate forced vibration results - in one case, these results were indistinguishable from those found using a best-fit loss coefficient.

\section{CONCLUSION}

This paper briefly introduced a previously-derived model of a multi-body half-car system with a hydraulically interconnected suspension. A unique, purpose-built halfcar test rig was described and used to validate the proposed model. The obtained results suggest that the modeling approach is sound for simulating vehicle response under certain conditions. More specifically, good agreement was found between the theoretical and experimental frequency responses when a harmonic force of $0-20 \mathrm{~Hz}$ and $\pm 2.6 \mathrm{~mm}$ nominal amplitude was applied to the left unsprung mass.

Although the experimental frequency responses were well predicted by the theory, more detailed, componentlevel experimentation (and modeling) is recommended for predicting more accurately the system response to specific inputs under a variety of operating conditions.

\section{ACKNOWLEDGMENTS}

Financial support for this research was provided jointly by the Australian Research Council (ARC LP0562440) and the University of Technology, Sydney.

\section{REFERENCES}

1. M.C. Smith, G.W. Walker, Interconnected Vehicle Suspension. Journal of Automobile Engineering 219 (3) (2005) pp. 295-307.

2. J. Fontdecaba, Integral Suspension System for Motor Vehicles Based on Passive Components. SAE Technical Paper Series, SAE 2002-01-3105 (2002).

3. J.R. Wilde, G.J. Heydinger, D.A. Guenther, T. Mallin, A.M. Devenish, Experimental Evaluation of Fishhook Maneuver Performance of a Kinetic Suspension System. SAE Technical Paper Series, SAE 2005-010392 (2005).

4. W. Smith, N. Zhang, J. Jeyakumaran, Ride Simulations of a Half-car with a Hydraulically Interconnected Passive Suspension. FISITA-2006 World Automotive Congress, Japan (2006).

5. J. Jeyakumaran, W. Smith, N. Zhang, Transient Performance of a Hydraulically Interconnected Suspension System. FISITA-2006 World Automotive Congress, Japan (2006).

6. M. Ortiz, Principles of Interconnected Suspensions. RaceCar Engineering 7 (7-8) (1997).

7. N. Zhang, W.A. Smith, J. Jeyakumaran, Hydraulically Interconnected Vehicle Suspension: Background and Modeling. Under review for Vehicle System Dynamics (2008).

8. E.B. Wylie and V.L. Streeter, Fluid Transients. McGraw-Hill, NY (1978).

9. D.N. Johnston, D.K. Longmore, J.E. Drew, A technique for the measurement of the transfer matrix characteristics of two-port hydraulic components. ASME Winter Annual Meeting, Chicago (1994).

10. W.T. Thomson, Theory of Vibration With Applications, Allen \& Unwin, London (1988).

11. M. Rozyn, Estimation of Vehicle Inertial Parameters. PhD Thesis, University of Technology, Sydney, 2008.

12. J.C. Dixon, The Shock Absorber Handbook. SAE International, Warrendale, Pa. (1999).

13. F.G. Guzzomi, P.L. O'Neill, A.C.R. Tavner, Investigation of Damper Valve Dynamics Using Parametric Numerical Methods. 16th Australasian Fluid Mechanics Conference, Gold Coast, Australia (2007) pp. 1123-1130.

14. D.N. Johnston, Measurement and Prediction of the Fluid Borne Noise Characteristics of Hydraulic Components and Systems. PhD Thesis, University of Bath (1987).

15. ISO 2631-1:1997, Evaluation of human exposure to whole-body vibration - Part 1: General requirements. 
16. K.A. Edge, D.N. Johnston, The impedance characteristics of fluid power components: relief valves and accumulators. Proc IMechE, Part I, J. Systems \& Control Eng. 205 (1991) pp. 11-22.

17. D.N. Johnston, K.A. Edge, The impedance characteristics of fluid power components: restrictor and flow control valves. Proc IMechE, Part I, J. Systems \& Control Eng. 205 (1991) pp. 3-10.

\section{CONTACT}

Wade Smith

Mechatronics and Intelligent Systems

Faculty Of Engineering

University of Technology, Sydney

PO Box 123, Broadway

NSW 2007, Australia

Ph: (02) 95142662

Fax: (02) 95142655

email: wsmith@eng.uts.edu.au 